Infusionstherapie 1992;19:265

\title{
Impressum, Vol. 19, No. 6, 1992
}

Impressum Offizielles Organ

der Deutschen Gesellschaft für Transfusionsmedizin

und Immunhämatologie

Gründungsherausgeber

H. Reissigl, Innsbruck

Herausgeber

J. Eckart, Augsburg V. Kretschmer, Marburg K. Meßmer, München K. Peter, München W.

Stangel, Hannover K.-H. Usadel, Frankfurt

Schriftleiter

H. Forst, München

Ässistent des Schriftleiters

B. Zwißler, München

Wissenschaftlicher Beiraí

M. Adolph, Augsburg

FW. Ahnefeld, Ulm

J. Askanazi, New York

C. Baldamus, Köln

H. Bardenheuer, München

J.-F Baron, Paris

K.-H. Bäßler, Mainz

W. Behrendt, Aachen

H. Borberg, Köln

U. B. Bruckner, Ulm

W. Dick, Mainz

J. Eckart, Augsburg

R. Eckstein, Erlangen

A. Encke, Frankfurt

K. Falke, Berlin

U. Finsterer, München

H. Forst, München

L. Frey, München

Y. Fujita, Okayama

L. Gattinoni, Monza

M. Georgieff, Ulm

A. Grünert, Ulm

H. J. Gurland, München

P. Hanfland, Bonn

M. Heberer, Basel 


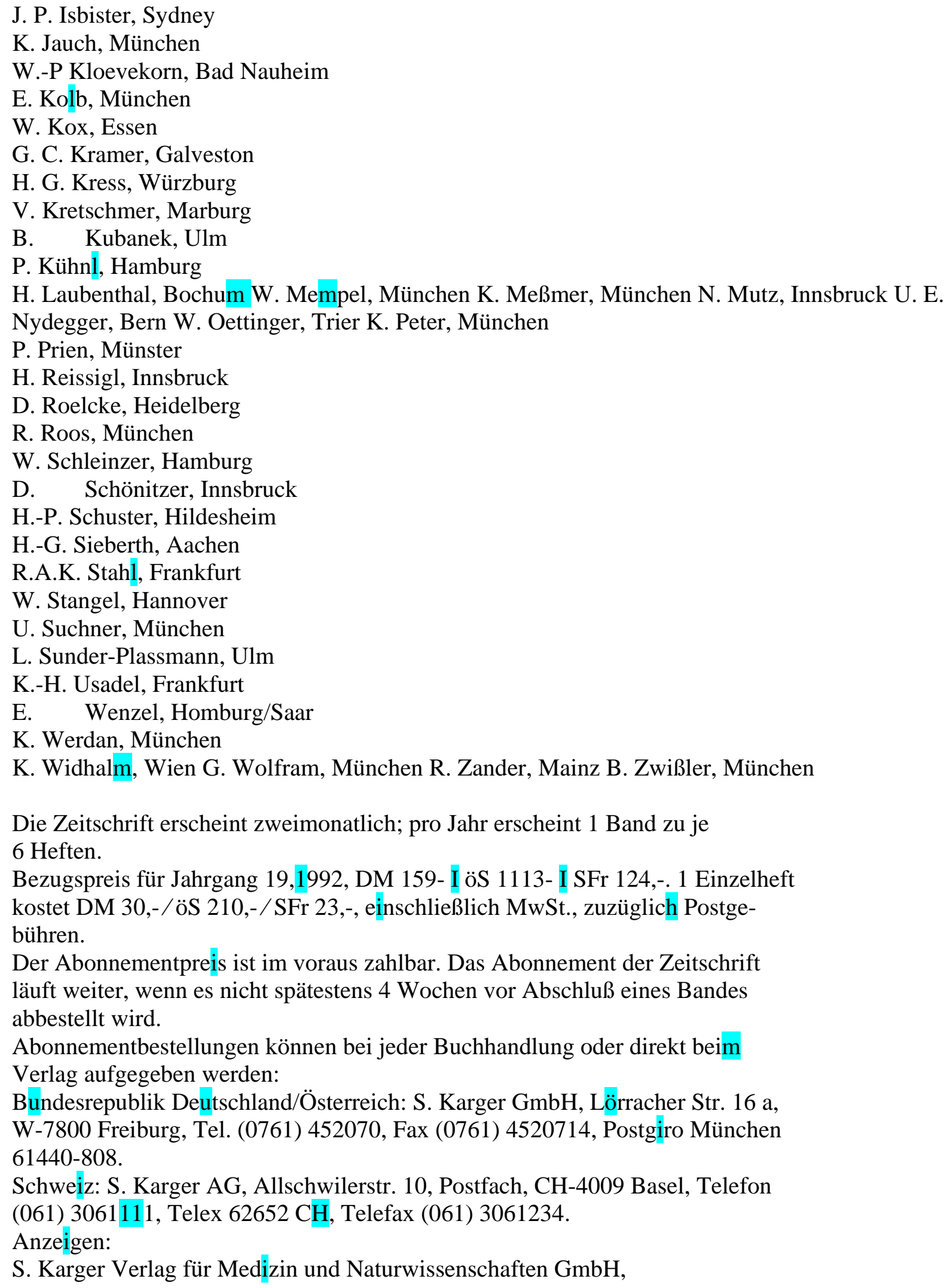


Lörracher Str. 16 a, W-7800 Freiburg, Tel. (0761) 452070.

Gültig ist die Preisliste Nr. 9 vom 1.10.1990.

Für den Inhalt außerhalb des redaktionellen Teiles (insbesondere Anzeigen, Industrieinformationen, Pressezitate und Kongreßinformationen) übernehmen Schriftleitung, Beirat und Verlag keine Gewähr.

Eine Markenbezeichnung kann warenzeichenrechtlich geschützt sein, auch wenn bei ihrer Verwendung in dieser Zeitschrift das Zeichen ${ }^{\circledR}$ oder ein anderer Hinweis auf etwa bestehende Schutzrechte fehlen sollte. Für Satzfehler, insbesondere bei Dosierungsangaben, wird keine Gewähr übernommen.

Die Zeitschrift sowie alle in ihr enthaltenen einzelnen Beiträge und Abbildungen sind urheberrechtlich geschützt. Jede Verwertung, die nicht ausdrücklich vom Ur-heberrechtsgesetz zugelassen ist, bedarf der vorherigen Zustimmung des Verlags. Das gilt insbesondere für Vervielfältigungen, Bearbeitungen, Übersetzungen, Mi-kroverfilmungen und die Einspeicherung und Verarbeitung in elektronischen Sy-stemen. Fotokopien dürfen nur für den persönlichen Gebrauch als Einzelkopien hergestellt werden. Jede im Bereich eines gewerblichen Unternehmens zulässig hergestellte oder benutzte Kopie dient gewerblichen Zwecken gem. § 54(2) UrhG und verpflichtet zur Gebührenzahlung an die Verwertungsgesellschaft WORT, Abt. VG Wissenschaft, Goethestraße 49, W-8000 München 2.

(C) Copyright 1992 by S. Karger

Verlag für Medizin und Naturwissenschaften GmbH

Lörracher Str. 16 a, W-7800 Freiburg (BRD)

Verlagsleitung: Steven Karger

Presserechtlich verantwortlich: Georg Brunner

Redaktionsassistenz: Martina Zeller

Anzeigenverwaltung: Christiane Opitz

Satz und Druck: Walter Biering GmbH

Grafischer Betrieb

Freisinger Landstraße 21

W-8000 München 45 (BRD)

KARGER 